\title{
Variation of the microtubular cytoskeleton organi- zation in representatives of the genus Pelomyxa (Amoebozoa, Archamoebae, Pelobiontida)
}

\author{
Ludmila Chistyakova ${ }^{1}$, Mariia Berdieva², Victor Tsarev ${ }^{3}$ \\ and Alexander Frolov ${ }^{1}$ \\ ${ }^{1}$ Zoological Institute, Russian Academy of Sciences, 199034 St. Petersburg, Russia \\ ${ }^{2}$ Institute of Cytology, Russian Academy of Sciences, 194064 St. Petersburg, Russia \\ ${ }^{3}$ St. Petersburg State University, 199034 St. Petersburg, Russia
}

| Submitted June 23, 2020| Accepted August 10, 2020|

\begin{abstract}
Summary
The structure of the microtubular cytoskeleton was studied in four species of the genus Pelomyxa: P. gruberi, P. belevskii, P. binucleata and P. stagnalis. We characterized in detail the spatial organization of the microtubular cytoskeleton in the cells of these protists with the help of immunofluorescent staining combined with TEM. The microtubular cytoskeleton consisted of three main components: the flagellar apparatus, the microtubules associated with the outer nuclear membrane and the cytoplasmic microtubules. In all the four species of Pelomyxa examined in this study, the organization of the basal apparatus of different flagella could vary even in the same individual. This variation, possibly associated with the morphophysiological polarity of the cells, may be determined by the position of the flagella on the long axis of the pelomyxa's body.
\end{abstract}

Key words: Archamoebae, Pelomyxa, immunofluorescent staining, tubulins, cytoskeleton

\section{Introduction}

Archamoebae are free-living or parasitic members of the group Amoebozoa, occurring under anaerobic or microaerobic conditions (Ptáčková et al., 2013; Zadrobílková et al., 2015; Panek et al., 2016; Kang et al., 2017). Archamoebae are highly unusual protists lacking mitochondria, peroxisomes and morphologically differentiated dictyosomes. Derivatives of mitochondria have been found only in two species of archamoebae: Entamoeba histoly- tica (mitosomes) and Mastigamoeba balamuthi (hydrogenosomes) (Tovar et al., 1999; Nývltová et al., 2013).

The group Archamoebae comprises: (1) amoeboflagellates capable of active locomotion with the help of flagella and generally moving by gliding on the substrate (Mastigamoeba, Mastigella, Rhizomastix); (2) amoeboflagellates with flagella uninvolved in locomotion (Pelomyxa, Mastigina, Tricholimax); (3) amoebae that lost the flagellar apparatus altogether (Entamoeba, Endamoeba, Endolimax, Iodamoeba

doi:10.21685/1680-0826-2020-14-3-4 
and, possibly, some Pelomyxa) (Cavalier-Smith et al., 2016). The ancestor of archamoebae was probably a Mastigamoeba-like organism that used the flagellum for locomotion but was also capable of amoeboid movement (Cavalier-Smith et al., 2015). Transition to the mostly amoeboid locomotion must have occurred several times in the evolution of this group, and was always accompanied by significant reorganizations of the cytoskeleton.

Microtubular skeleton of archamoebae from the genus Pelomyxa is of special interest. In these protists, the formation of amoeboid type of cell organization was accompanied by a considerable increase in size and the polymerization of the nuclear and the flagellar apparatus (Frolov, 2011; Chistyakova et al., 2013; Ptáčková et al., 2013; Zadrobílková et al., 2015). Most known pelomyxae have flagella, which are generally immotile. The structure of the axoneme and the kinetosome in these flagella is often aberrant, which appears to be associated with the loss of their locomotor function (Seravin and Goodkov, 1987; Goodkov, 1989; Frolov, 2011).

A more or less developed microtubular cytoskeleton has been described in several pelomyxae with the help of TEM. It can be represented by: (1) cytoplasmic microtubular derivatives of kinetosomes (rootlets); (2) perinuclear microtubules associated with the outer nuclear membrane; (3) cytoplasmic microtubules (Chistyakova et al., 2013). By analogy with Mastigamoebidae (Walker et al., 2001), several well-differentiated groups of microtubules can be distinguished in the rootlet system of the kinetosomes in pelomyxae: (1) radial microtubules, radiating from the lateral surface of the kinetosome in one or several rows and forming a cone or a bundle mostly situated in the surface layer of the cytoplasm; (2) a lateral rootlet represented by a band of tightly adjoining microtubules, starting from the electron-dense material on the lateral surface of the kinetosome and located in the ectoplasm under the cell membrane; (3) basal microtubules starting from a MTOC at the base of the kinetosome; they often form a bundle directed into the cytoplasm (Chistyakova et al., 2013, 2014; Berdieva et al., 2015).

However, a complete picture of the tubulin cytoskeleton organization in pelomyxae cannot be obtained with the use of TEM alone. Large size of these protists and their strongly vacuolated cytoplasm filled with numerous inclusions make it difficult a spatial reconstruction of their cytoske- leton. The aim of this study was to obtain a complete picture of the organization of microtubular cytoskeleton in the cells of four species of Pelomyxa by using immunofluorescent staining combined with traditional electron microscopic methods.

\section{Material and methods}

\section{SAMPLING AND LIGHT MICROSCOPY}

The structure of microtubular cytoskeleton was studied in Pelomyxa gruberi, P. belevskii, P. binucleata and $P$. stagnalis. The pelomyxae were isolated from the bottom sediments sampled in Ceratophyllum Pond (St. Petersburg, Staryi Petergof, Sergievka Park) and in Afanas'ev Pond (Lyady Village, Pskov Region) in spring and summer of 2019.

The samples were stored in the fridge at $10{ }^{\circ} \mathrm{C}$. To isolate the pelomyxae, 3-4 $\mathrm{ml}$ of the bottom sediments (detritus) were put into a Petri dish with a diameter of $90 \mathrm{~mm}$, diluted with pond water 1:1 and viewed under a Leica $125 \mathrm{C}$ stereomicroscope (Leica-Microsystems, Wetzlar, Germany). Light microscopic observations and microphotographs were made with the use of Leica DM2500 microscope equipped with Nomarski contrast, a fluorescent module and a Leica DFM 495 camera (Leica-Microsystems, Wetzlar, Germany). Actively moving amoebae were selected and fixed for the subsequent studies.

\section{AntiBodies}

Primary antibodies used for immunofluorescent staining of the microtubular cytoskeleton in Pelomyxa species were monoclonal anti- $\alpha$-Tubulin antibodies produced in mouse (T5168, SigmaAldrich, USA). These antibodies have been successfully used in our previous studies of protists from other taxonomic groups (Berdieva et al., 2018). To verify indirectly the specificity of antibody binding, we compared $\alpha$-tubulin sequences of representatives of Archamoebae with a sequence of Mus musculus tubulin $\alpha$-1A chain (NP_035783.1). In the absence of available Pelomyxa sequences, E. histolytica tubulin $\alpha$ chain amino acid sequence (EAL48031.1) and M. balamuthi translated "similar to tubulin alpha chain" nucleotide sequence (BM320995.1) were used as queries. The analysis was performed using BLASTP and BLASTX (with standard genetic code) algorithms, respectively (https://blast.ncbi.nlm.nih. 
gov/Blast.cgi). The analysis revealed 53.02\% identity (e-value $=0.0,98 \%$ query cover) for E. histolytica, and $89.19 \%$ identity (e-value $=9 \mathrm{e}-73,73 \%$ query cover) for $M$. balamuthi. We also observed a high similarity of aligned sequences in the C-terminal region, which, according to the provider's data, contains the epitope recognized by the antibody.

\section{IMMUNOFLUORESCENT LABELLING AND MICROSCOPY}

The amoebae were fixed with $4 \%$ paraformaldehyde in PBS for 30 min and washed in PBS thrice for $5 \mathrm{~min}$ each time. After that, the cells were treated with $1 \%$ Triton $\mathrm{X}-100$ for $20 \mathrm{~min}$, washed in PBS thrice for 5 min each time and blocked with $1 \%$ BSA for $10 \mathrm{~min}$. Then the cells were put into Eppendorf tubes in a minimum amount of liquid, mixed with $20 \mu \mathrm{l}$ of primary antibodies (diluted with PBS 1:500), and incubated at $+4^{\circ} \mathrm{C}$ overnight. Then the cells were washed thrice in PBS, transferred into another Eppendorf tube and mixed with $20 \mu \mathrm{l}$ of secondary antibodies Anti-Mouse IgG (whole molecule)-TRITC antibody produced in goat Sigma-Aldrich T5393 (diluted with PBS 1:100), incubated in the dark at room temperature for 1.5 $h$. The preparations were washed thrice in PBS and embedded into glycerine with addition of DAPI (1351303, Bio-Rad, USA) $(2 \mu \mathrm{g} \backslash \mathrm{ml})$ or SYTO 24 Green (S7559, Thermofisher, USA) (500 nM). They were viewed under a Leica DM2500 microscope with a fluorescent module with the use of filter cube $\mathrm{B} \backslash \mathrm{G} \backslash \mathrm{R}, \mathrm{N} 2.1$ and I3 (Leica-Microsystems, Wetzlar, Germany).

\section{TRANSMISSION ELECTRON MICROSCOPY}

Material for electron microscopy was prepared as described before (Frolov et al., 2005a, 2006) and studied with the use of microscopes Tesla BS500 (Tesla, Brno, Czech Republic) and Zeiss Libra 120 (Carl Zeiss, Oberkochen, Germany).

\section{Results}

\section{PELOMYXa GRUBeri}

These pelomyxae usually move little in the samples. During directed locomotion they form a broad leading lobose pseudopodium and small hyaline conical or finger-shaped lateral outgrowths (Fig. 1, A). There is an uroid at the posterior end of a moving cell, represented by small hyaline villi of various shape. The cells reach the length of 250-300 $\mu \mathrm{m}$.

Immotile flagella, 5-7 $\mu \mathrm{m}$, are mostly found in the uroidal zone. A strongly developed rootlet system associated with the kinetosomes can be seen even at the light microscopic level (Fig. 1, A, inset).

Numerous flagella and the associated elements of the basal apparatus visualized clearly in the cells stained with the use of anti- $\alpha$-tubulin antibodies (Fig. 2, A-C). A cell could bear 10 and more flagella. They usually concentrated in the uroidal zone, but sometimes were also present on the lateral cell surface. At the base of most flagella in the uroidal zone, there was a distinct fluorescent zone about $1.5-2 \mu \mathrm{m}$ in diameter, from which radial microtubules started at an angle to the longitudinal axis of the flagellum (Fig. 2, A, B). In addition, a bundle of basal microtubules went into the cytoplasm as if in continuation of the flagellum; the bundle was $10-15 \mu \mathrm{m}$ long, wider at the base of the basal body and tapering towards the end (Fig. 2, A, B). These differentiated elements of the kinetosome were strongly reduced or altogether lacking in the flagella on the lateral side of the cell, and only a small accumulation of fluorescent material was visible (Fig. 2, C).

It could be seen in ultra-thin sections of the flagella in the uroidal zone that the kinetosomes were surrounded with a more or less pronounced accumulation of electron-dense material (a "muff"). Numerous radial microtubules started in all directions along the entire length of the kinetosome, in parallel to the cell membrane or at a slight angle to it (Fig. 2, K-M). A bundle of tightly packed basal microtubules went from the kinetosome base into the cytoplasm (Fig. 2, K). The number of radial microtubules of the basal bodies of the flagella on the lateral cell surface was much smaller, and they lacked any pronounced basal bundle at the base (Fig. 2, J).

The cells of $P$. gruberi had large accumulations of microtubules associated with the outer nuclear membrane (Fig. 2, D-H). Immunofluorescent staining against $\alpha$ tubulin revealed a distinct halo around the nucleus, from which fluorescent strands radiated into the cytoplasm in different directions. Their length could reach 20-25 $\mu \mathrm{m}$ (Fig. 2, D, E). Accumulations of numerous variously oriented microtubules around the nuclei could be seen in ultra-thin sections (Fig. 2, F-H). Finally, separate bundles of microtubules were found in various areas of the cytoplasm (Fig. 2, H, I, M). 

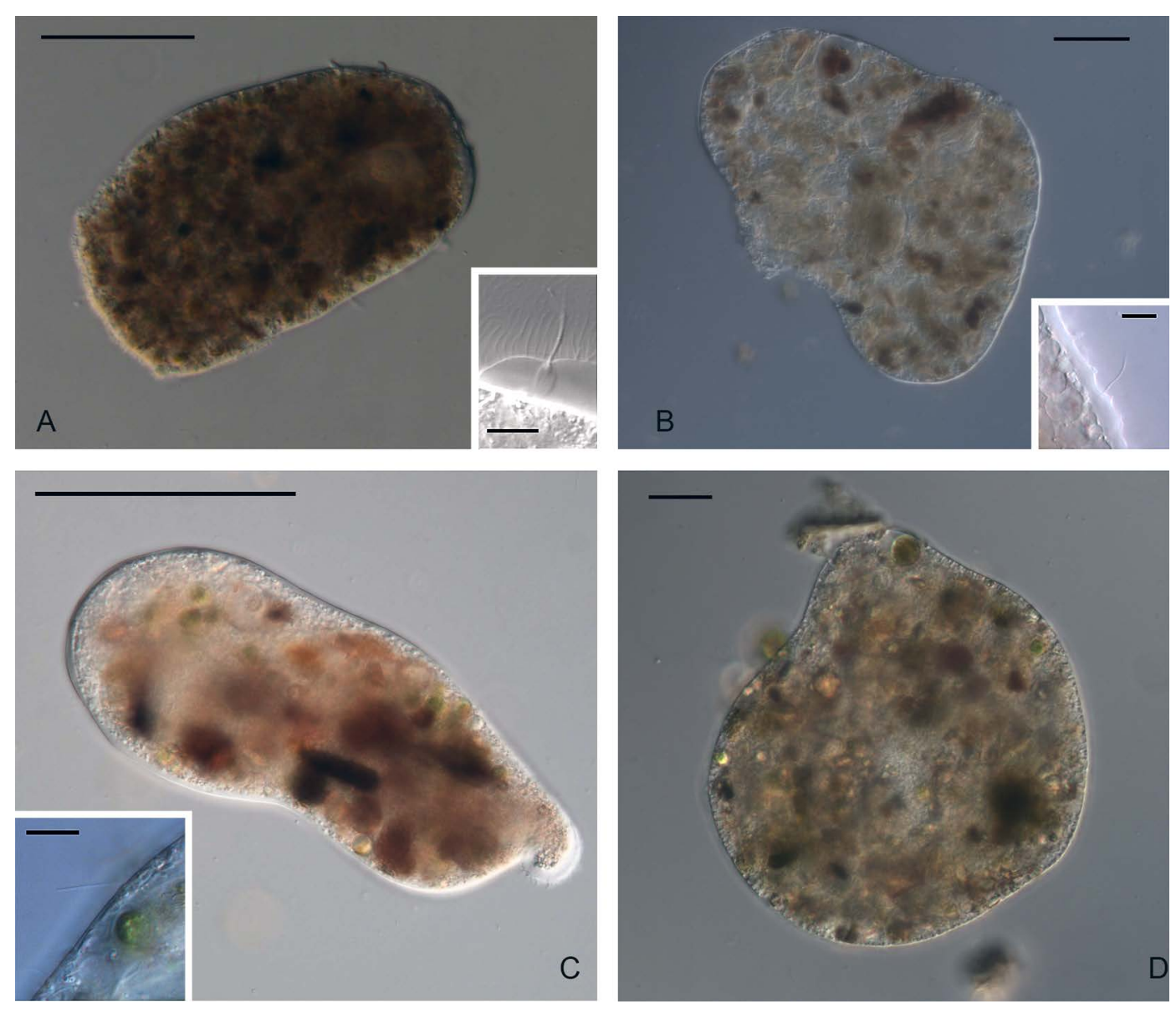

Fig. 1. General morphology of pelomyxae. A - P. gruberi, B - P. belevskii, C - P. binucleata, D - P. stagnalis. Scale bars: $100 \mu \mathrm{m}$, insets: $20 \mu \mathrm{m}$.

\section{PELOMYXA BELEVSKII}

These pelomyxae move little. Their cells are oval or almost rounded (Fig. 1, B), reaching 400-500 $\mu \mathrm{m}$ in diameter. The cell elongates slightly during directed locomotion. Branching hyaline villi are present in the uroidal zone.

Numerous short immotile flagella could be easily seen between the hyaline villi (Fig. 1, B, inset). With the use of immunocytochemical methods, large groups of flagella were revealed both in the uroidal zone and on the lateral cell surface (Fig. 3, A-C). Two types of the basal apparatus of flagella could be seen in one and the same cell. The first type is characterised by the presence of a dense bundle of microtubules starting from the kinetosome, its length reaching 25-30 $\mu \mathrm{m}$ (Fig. 3, A, C). These bundles are often almost parallel to each other in neighbouring flagella (Fig. 3, C). The second type is characterised by the presence of a cylindrical,
$1.5-2 \mu \mathrm{m}$-long body at the base of the flagellum, from which a short bundle of microtubules rarely arises (Fig. 3, B). Flagella with the basal apparatus of the first type were mostly found in the uroidal zone, while those with the basal apparatus of the second type were mostly found at the lateral cell surface.

Numerous radial microtubules forming a rather dense bundle arose from the lateral surface of the kinetosomes, as could be easily seen in electron micrographs of the uroidal zone (Fig. 3, G, H). Indistinct radial symmetry in their arrangement could be discerned at the transverse sections of the bundles (Fig. 3, F). There were up to 30-40 microtubules at a section.

At the base of the flagella located closer to the lateral body surface there was a relatively small bundle consisting of several microtubules and oriented almost in parallel to the cell membrane (Fig. 3, H, inset). 

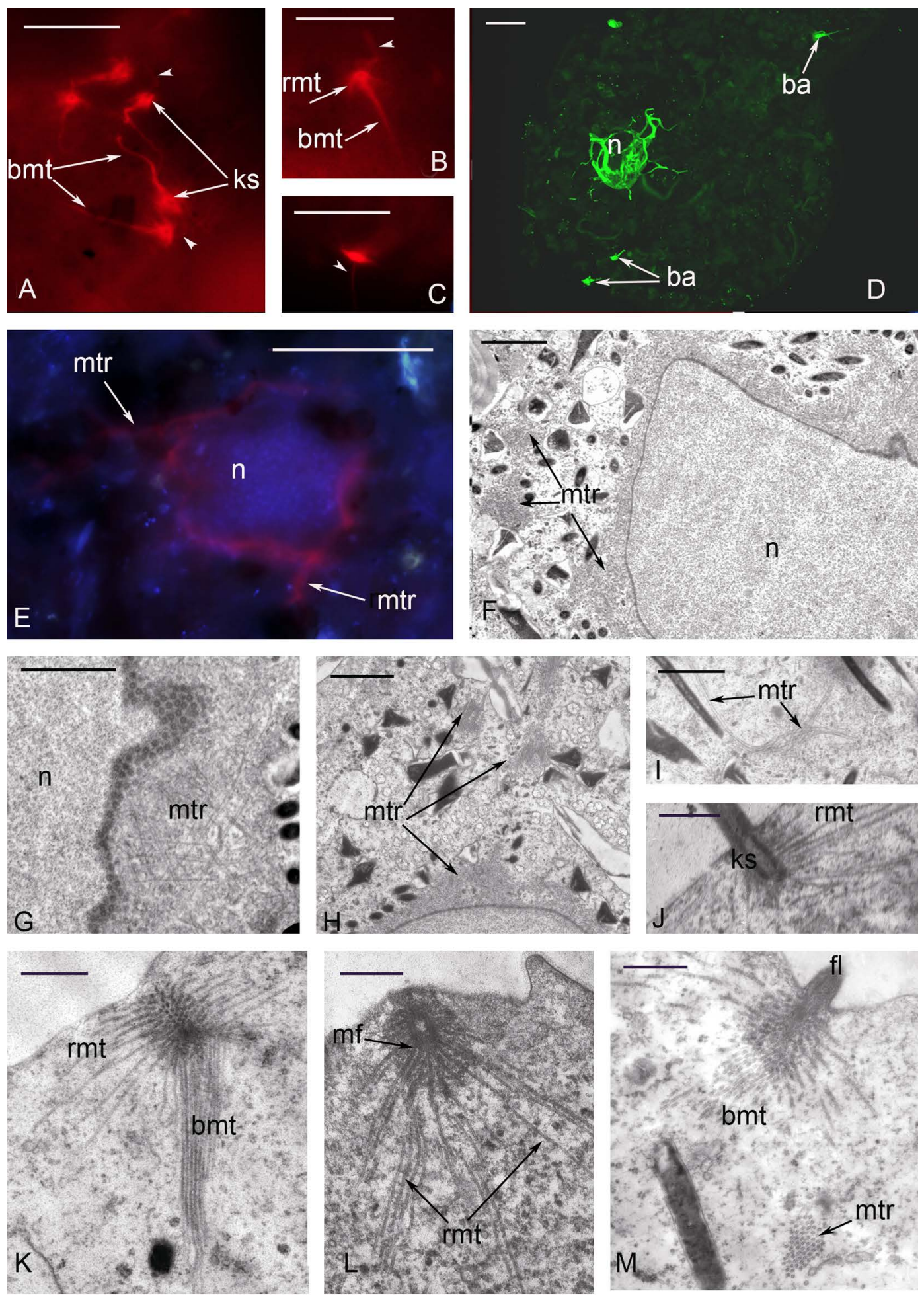

Fig. 2. Organisation of microtubular cytoskeleton in P. gruberi. A-E - Immunofluorescent staining: A - a group of flagella in the uroidal zone, B, C, - single flagella, D - a uninucleate P. gruberi, E - microtubules around the nuclei; F-M - TEM: F-H - microtubules around the nuclei, I - bundles of microtubules in the cytoplasm, J-M - structure of flagellar apparatus. Abbreviations: ba - basal apparatus, bmt - basal microtubules, $\mathrm{fl}$ - flagella, ks - kinetosome, $\mathrm{mtr}$ - microtubules, $\mathrm{rmt}$ - radial microtubules, $\mathrm{mf}$ - a "muff" of electron-dense material, $\mathrm{n}$ - nucleus; arrowheads - flagella. Scale bars: A, B, C - $10 \mu \mathrm{m}, \mathrm{D}, \mathrm{E}-25 \mu \mathrm{m}, \mathrm{F}, \mathrm{H}, \mathrm{I}-2 \mu \mathrm{m}, \mathrm{G}$, $\mathrm{J}-\mathrm{M}-1 \mu \mathrm{m}$. 

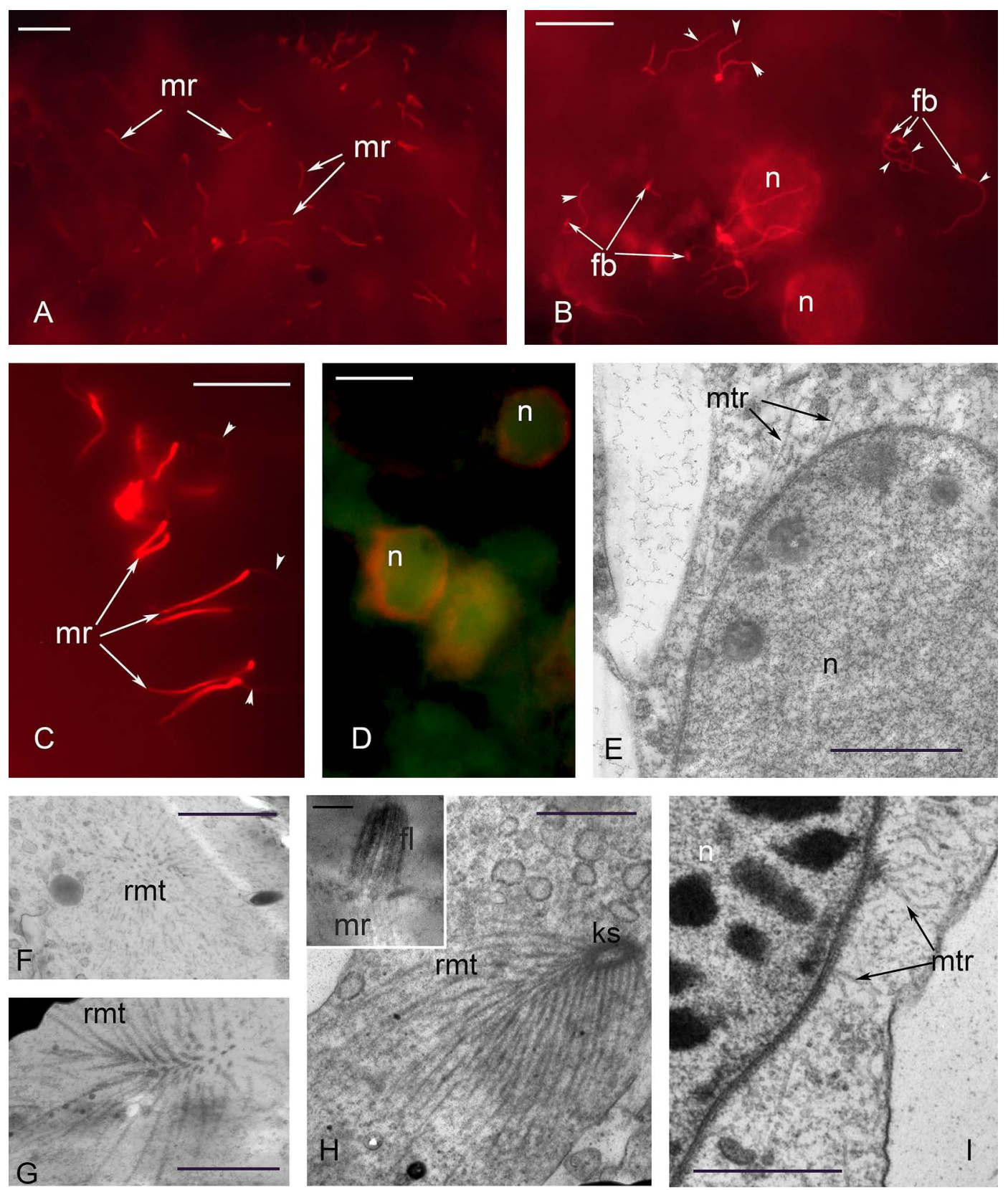

Fig. 3. Organisation of microtubular cytoskeleton in P. belevskii. A-D - Immunofluorescent staining: A, C a group of flagella in the uroidal zone, B - an area at the side of pelomyxa's body (note microtubules around the nuclei and numerous flagella), D - microtubules around the nuclei; E-I - TEM: F-H - sections of rootlet structures of the flagellar apparatus, E, I - microtubules associated with the outer nuclear membrane. Abbreviations: $\mathrm{fb}$ - fluorescent body, $\mathrm{mr}$ - microtubular rootlet, other abbreviations as in Fig. 1; arrowheads flagella. Scale bars: A, B, C, D - $20 \mu \mathrm{m}, \mathrm{D}, \mathrm{E}, \mathrm{F}, \mathrm{G}, \mathrm{H}, \mathrm{I}-1 \mu \mathrm{m}$, inset in H $-250 \mathrm{~nm}$.

A distinct fluorescent rim could be seen around the nuclei of $P$. belevskii (Fig. 3, B, D). Irregular short $(1-2 \mu \mathrm{m})$ microtubules associated with the outer nuclear membrane could be seen in the electron micrographs (Fig. 3, E, I).

\section{PELOMYXa BINUCLEATA}

The amoebae of this species move rather actively, and are cylindrical in shape during locomotion. A bulbous uroid with a pronounced hyaline rim is 

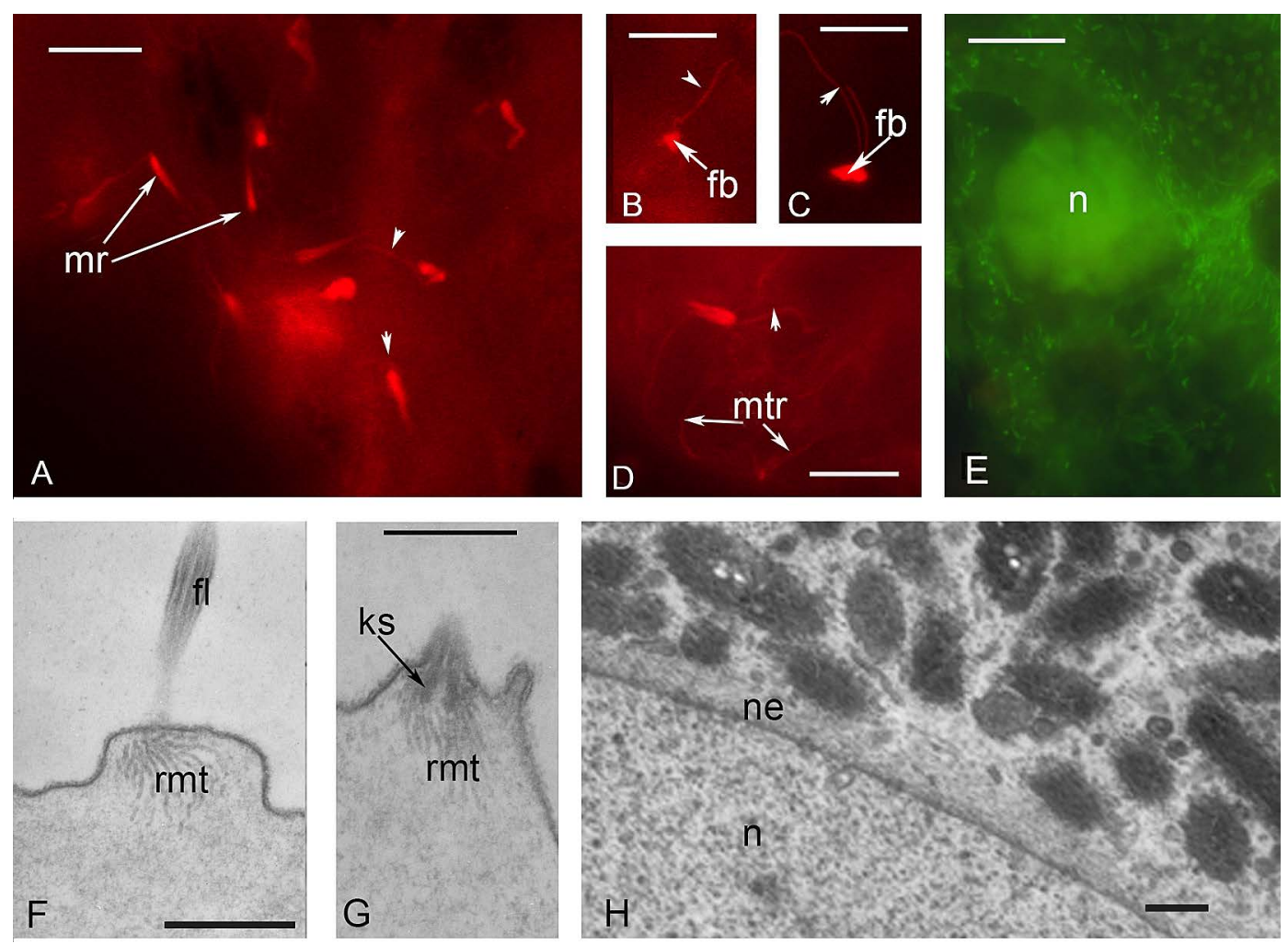

Fig. 4. Organisation of microtubular cytoskeleton in P. binucleata. A-D - Immunofluorescent staining: A - a group of flagella in the uroidal zone, B-D - single flagella on the cell surface; E - SYTO Green staining, F- I - TEM; F, G - structure of the flagellar apparatus, H, I - structure of the nucleus. Abbreviations: mtr - microtubules, $\mathrm{fl}$ - flagella, $\mathrm{rmt}$ - radial microtubules, $\mathrm{ks}$ - kinetosome, $\mathrm{mr}$ - microtubular rootlet, $\mathrm{fb}$ fluorescent body, $\mathrm{n}$ - nucleus, ne - nuclear envelope; arrowheads - flagella. Scale bars: A, B, C, D - $10 \mu \mathrm{m}$, $\mathrm{E}-20 \mu \mathrm{m}, \mathrm{F}, \mathrm{G}, \mathrm{H}-1 \mu \mathrm{m}, \mathrm{I}-3 \mu \mathrm{m}$.

often present (Fig. 1, C). Cytoplasmic flows are wellvisible inside the cell. Flagella are usually located in the uroidal zone (Fig. 1, C, inset). Though entirely uninvolved in locomotion, they may oscillate or rotate around the bases.

More or less loose bundles of microtubules, sometimes resembling a tassel, could be seen at the base of most flagella at immunofluorescent preparations. They could reach $6-7 \mu \mathrm{m}$ in length (Fig. 4, A, D). At the base of some flagella, however, there were no such bundles, and all that could be seen were cylindrical or conical fluorescent bodies, 1.5-2 $\mu \mathrm{m}$ long (Fig. 4, B, C), which were probably kinetosomes. Sometimes two such bodies adjoined each other so tightly that the border between them was indistinct, but the two flagella starting from them could still be seen (Fig. 4, C). Thin variously directed fluorescent strands of microtubules could also be seen in the cytoplasm of P. binucleata (Fig. 4, D).

Radial microtubules arising from the kinetosome could be seen very well in ultra-thin sections (Fig.
4, F, G). They formed a bundle directed at a small angle to the cell surface There were about 20-30 microtubules in a bundle.

No microtubules associated with the nuclear envelope were revealed either by immunofluorescent staining or by TEM (Fig. 4, E, H).

\section{PeLOMYXa STAGNALIS}

During directed locomotion these pelomyxae are oval or pear-shaped, with a broadened anterior end (Fig. 1, D). A bulbous uroid forms sometimes at the posterior body end.

Numerous flagella could be seen in immunofluorescent preparations of $P$. stagnalis. A small bundle of microtubules, 5-7 $\mu \mathrm{m}$ long, arises from the flagellum base (Fig. 5, A-C). The orientation of the bundle varies. Sometimes it is parallel to the body surface and adjoins the cell membrane closely (Fig. 5, D). Numerous bundles of microtubules with various orientation can be seen in the cytoplasm (Fig. 

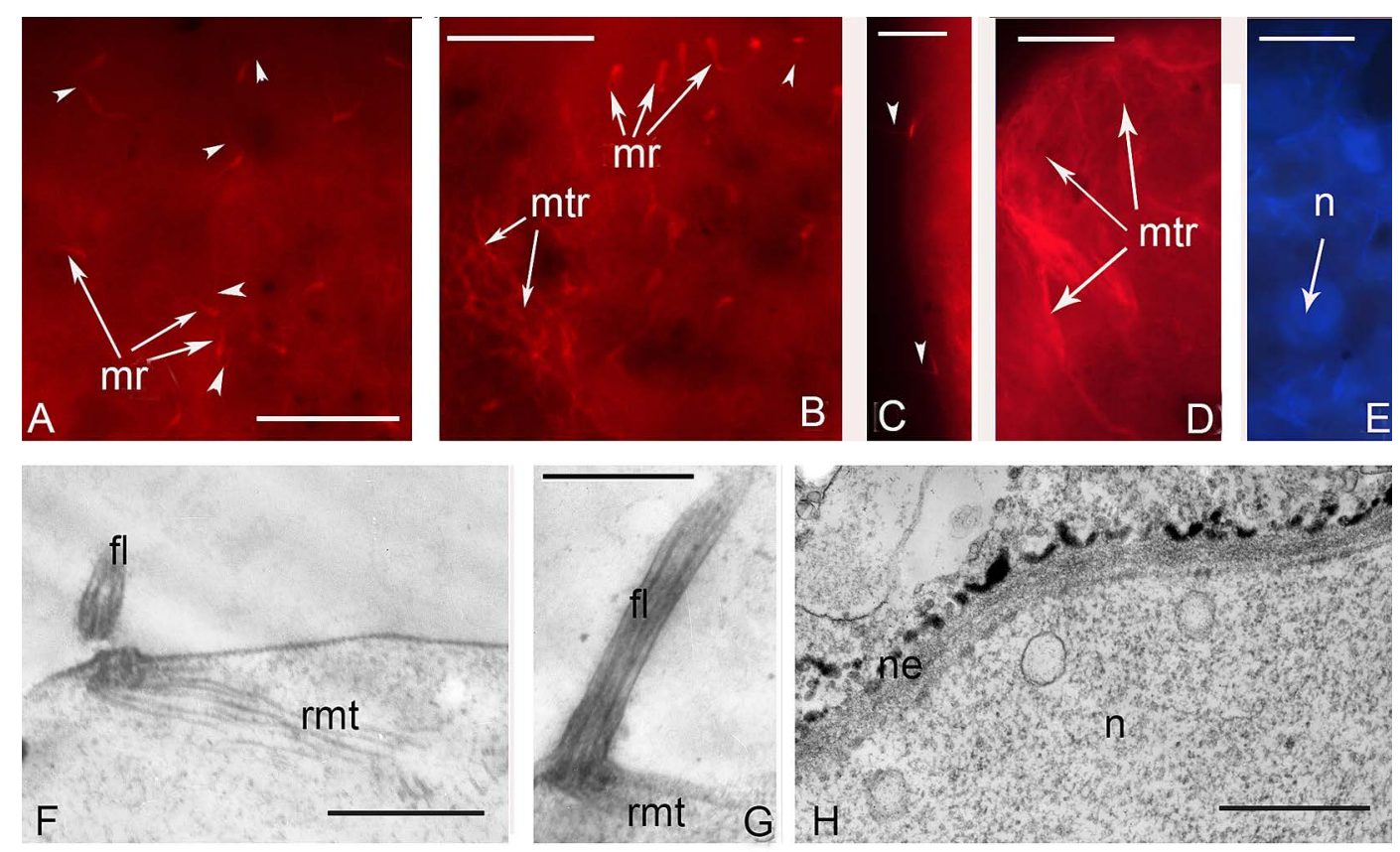

Fig. 5. Organisation of microtubular cytoskeleton in P. stagnalis. A-D - Immunofluorescent staining: A-C - single flagella and their groups, D - a network of cytoplasmic microtubules in the uroidal zone; E - DAPI staining; F-I - TEM. F, G - Structure of the flagellar apparatus, H, I - an area of the nucleus. Abbreviations: $\mathrm{mtr}$ - microtubules, $\mathrm{fl}$ - flagella, $\mathrm{rmt}$ - radial microtubules, $\mathrm{mr}$ - microtubular rootlet, $\mathrm{ks}$ - kinetosome, $\mathrm{n}$ nucleus, ne - nuclear envelope; arrowheads - flagella. Scale bars: A, B, D, E - $20 \mu \mathrm{m}, \mathrm{C}-5 \mu \mathrm{m}, \mathrm{F}, \mathrm{G}, \mathrm{H}-1$ $\mu \mathrm{m}, \mathrm{I}-2 \mu \mathrm{m}$.

5, B, D). The network of cytoplasmic microtubules is especially distinct in the uroidal zone (Fig. 5, D).

It can be seen in electron micrographs that not more than 10 radial microtubules, arranged almost in parallel to each other in a small bundle, arise from the lateral surface of the kinetosome. The bundle is almost parallel to the body surface or lies at a small angle to the cell membrane (Fig. 5 F, G).

The cytoplasmic side of the nuclear envelope in $P$. stagnalis has a complex structure. A multilamellar layer lies on the outside of the nuclear envelope, followed by a layer of small vesicles. Neither separate microtubules nor any microtubular structures associated with the nuclear envelope could be seen (Fig. $5 \mathrm{H}, \mathrm{I})$.

\section{Discussion}

The first species of Pelomyxa, which was shown to have a well-developed microtubular cytoskeleton, was P. palustris (Seravin and Goodkov, 1987; Griffin, 1988; Goodkov, 1989). However, while Griffin (1988) reported a developed microtubular system associated with the outer nuclear membrane, Sera- vin and Goodkov (Seravin and Goodkov, 1987; Goodkov, 1989) noted nothing of this kind. Since the genus was considered monotypic at that time, all pelomyxae were automatically attributed to $P$. palustris (Whatley and Chapman-Andersen, 1990). Later the concept of monotypy of Pelomyxa was shown to be invalid (Goodkov et al., 2004; Frolov, 2011). At present, this genus comprises 11 species, which have considerable morphological differences. It is fairly evident that the studies of Seravin and Goodkov (Seravin and Goodkov, 1987; Goodkov, 1989) on the one hand and the study of Griffin (1988) on the other hand involved different species of Pelomyxa. While the former authors indeed studied $P$. palustris, as verified later by Frolov et al. (2007), the species of the organism studied by Griffin (1988) cannot be identified based on the available data. Subsequently, numerous elements of the microtubular cytoskeleton have been found in all species of Pelomyxa studied in this respect (Frolov et al., 2004, 2005a, 2005b, 2006, 2011; Chistyakova et al., 2011, 2014; Berdieva et al., 2015) (Table 1). In this study, however, we characterized for the first time the general spatial organization the microtubular cytoskeleton in different pelomyxae, 
Table 1. Organisation of microtubular cytoskeleton in Pelomyxa spp.

\begin{tabular}{|c|c|c|c|c|c|c|c|}
\hline \multirow[t]{2}{*}{ Microtubules } & \multicolumn{3}{|c|}{ Basal apparatus of the flagellum } & \multicolumn{2}{|c|}{ Perinuclear microtubules } & \multicolumn{2}{|c|}{ Cytoplasmic microtubules } \\
\hline & $\begin{array}{l}\text { radial } \\
\text { microtubules }\end{array}$ & $\begin{array}{l}\text { basal } \\
\text { microtubules }\end{array}$ & $\begin{array}{l}\text { lateral } \\
\text { rootlet }\end{array}$ & $\begin{array}{l}\text { short, strictly parallel } \\
\text { to each other and } \\
\text { the nuclear envelope }\end{array}$ & $\begin{array}{l}\text { of various } \\
\text { length and } \\
\text { orientation }\end{array}$ & $\begin{array}{l}\text { Microtubular } \\
\text { network in the } \\
\text { endoplasm }\end{array}$ & Bundles of microtubules \\
\hline Pelomyxa corona & & & & & & + & in ecto- and endoplasm \\
\hline P. secunda & & & & + & & & \\
\hline P. flava & + & + & + & + & & & in ectoplasm \\
\hline P. paradoxa & + & & + & & & & \\
\hline P. prima & + & + & + & & + & & in endoplasm \\
\hline P. gruberi & + & + & & & + & & in endoplasm \\
\hline P. belevskii & + & & & & + & & \\
\hline P. binucleata & + & & & & & + & \\
\hline P. stagnalis & + & & & & & + & in endoplasm \\
\hline P. palustris & + & & & & & + & in ecto- and endoplasm \\
\hline
\end{tabular}

which was made possible owing to the use of immunofluorescent staining.

$P$. gruberi has the best-developed and complex microtubular cytoskeleton out of all the species of the genus examined in this study. Numerous microtubules are associated with the outer nuclear membrane. Their derivatives structure much of the rest of the cytoplasm by means of radiating long dense bundles. Though these structures had been observed in electron micrographs of $P$. gruberi before, in this study we finally ascertained their origin.

Most of the tubulin cytoskeleton in the uroidal zone of $P$. gruberi is composed by long dense bundles of basal microtubules starting from the base of the flagellar basal bodies. In the micrographs of the stained preparations, they look like spherical fluorescent bodies at the base of flagella because they are surrounded with a "muff" of tubulin-containing material. Radial microtubules start from these bodies and pass in various directions.

$P$. belevskii also has microtubules associated with the outer nuclear membrane. However, there are fewer of them than in P. gruberi, they are shorter and do not form bundles. The main component of the tubulin cytoskeleton in the cytoplasm of $P$. belevskii are long dense bundles of microtubules, which are radial in their origin, i.e. they start from the basal bodies of numerous flagella, mostly those in the posterior part of the cell.

In $P$. binucleata and $P$. stagnalis, flagellar rootlets are also formed by bundles of radial microtubules, but there are fewer microtubules per bundle in these species than in $P$. belevskii, and they are less densely packed. In contrast to $P$. gruberi and $P$. belevskii, flagellar rootlets in $P$. binucleata and $P$. stagnalis not very strongly involved in the organization of the general microtubular cytoskeleton. Besides, these pelomyxae lack microtubules associated with the nuclear envelope. At the same time, they have numerous microtubules penetrating the cytoplasm in various directions. This microtubular network is especially well-developed in the cytoplasm of $P$. stagnalis.

Unexpectedly, we found that $P$. belevskii, $P$. binucleata and $P$. gruberi possess, alongside with the "normal" flagella, also those with a considerably reduced or completely absent rootlet system. These "aberrant" flagella were especially numerous in $P$. belevskii.

The so-called "flagellar buds", which are newly forming flagella, have been noted earlier in electron micrographs of $P$. gruberi and P. palustris (Goodkov, 1989; Frolov et al., 2006). Such a flagellum forms from the basal body associated with the full set of rootlets characteristic of the species. A similar picture is observed in many members of Variosea and Eumycetozoa, forming clades related to Archamoebae on the phylogenetic tree of Amoebozoa (Kang et al., 2017). As the amoeboid stage of these protists transforms into a flagellar one, the flagellum starts to grow from the kinetosome after the rootlet system has already formed or, at least, these processes proceed in parallel to each other (Ishigami, 1977, Wright et al., 1981, Spiegel, 1981, 1985, Haskins, 1987). This picture is the opposite of what is observed in P. belevskii, P. binucleata and $P$. gruberi.

In the archamoeba Mastigina hylae, there are, besides the main kinetosome with a flagellum and a full set of microtubular rootlets, also kinetosomes with a reduced rootlet system (Brugerolle, 1982). 
However, these additional kinetosomes do not bear flagella.

Finally, a temporary resorption of the rootlet system has been noted in some other protists but it is always short-timed and always associated with cell division (see e.g., Johnson and Porter, 1968; Simpson and Dingle, 1971; Fritz-Laylin and Fulton, 2016).

It has been suggested that aberrations in the flagellar axoneme structure in $P$. palustris are associated with the loss of locomotor function and motility of the flagella (Seravin and Goodkov, 1987; Goodkov, 1989). Now we suggest that this loss also explains the structural aberrations of the components of the basal apparatus of pelomyxae: the kinetosome and the rootlet system.

An unexpected fact about the studied species of pelomyxae is that the reduction of the flagellar rootlet system may correlate with the position of the flagella along the longitudinal body axis of the moving cell. The flagella in the uroidal zone have a fully developed rootlet system, while those on the lateral body surface may have strongly reduced rootlet derivatives of the kinetosome or else even lack them altogether, as in, e.g., P. belevskii and $P$. binucleata.

Comparative morphological analysis of the Pelomyxa spp. under study showed that the general structure of the tubulin cytoskeleton is very similar in P. gruberi and P. prima. The latter species can be distinguished by the presence of the lateral rootlet in the basal apparatus (Frolov et al., 2004). P. binucleata and P. stagnalis are similar to $P$. palustris (Goodkov, 1989, Frolov et al., 2007) but out of these three species $P$. palustris has the most strongly reduced flagellar apparatus and the most strongly developed system of cytoplasmic microtubules. A well-developed network of cytoplasmic microtubules has been found in several protostelids (Variosea) and in plasmodia of slime moulds (Eumycetozoa) (Spiegel, 1991, Mayne and Adamatzky, 2015). All these protists, together with the archamoebae, belong to the group Evosea (Amoebozoa) (Kang et al., 2017).

In the other Archamoebae, microtubular cytoskeleton is mostly represented by the elements of the flagellar apparatus (Brugerolle, 1982, Chavez et al., 1986, Simpson et al.,1997, Walker at al., 2001, Ptáčková et al., 2013, Zadrobílková et al., 2015, 2016, Panek et al., 2016). All archamoebae without exception have radial microtubules in the rootlet system, which start from the lateral surface of the kinetosome in one or several layers. In
Mastigamoeba spp. and M. hylae these microtubules are involved in the formation of the karyomastigont (Brugerolle, 1982, Simpson et al.,1997, Walker at al., 2001, Chistyakova et al., 2012, Panek et al., 2016). In Mastigella spp. there is no connection between the nucleus and the flagellar apparatus, and radial microtubules form a bundle which usually lies in parallel or at a small angle to the cell surface (Walker at al., 2001, Zadrobílková et al., 2015, 2016). In this case, it can be seen at the transverse sections passing close to the kinetosome base that the microtubules form concentric circles. In some species of Pelomyxa, radial microtubules arise from the kinetosome to form a more or less broad cone; in such a case, the rootlet system usually includes basal microtubules as well. In some other species of Pelomyxa, radial microtubules form a bundle, and are almost parallel to each other in it. Finally, in Rhizomastix spp. radial microtubules form the rhizostyle, a dense bundle of microtubules extending into the cell and, as in $R$. libera, partly enveloping the nucleus (Zadrobílková et al., 2016).

Many archamoebae have a lateral rootlet, a band of tightly packed microtubules starting from the accumulation of electron-dense material associated with one of the lateral surfaces of the kinetosome. At the base of the flagellum in Mastigamoeba aspera and Mastigina hylae there is also a cone of microtubules that starts from a separate MTOC associated with the kinetosome base and tightly envelopes the anterior part of the nucleus (Brugerolle, 1982, Chistyakova et al., 2012). We assume that the basal microtubules of pelomyxae, which also start from a separate MTOC at the kinetosome base, may be homologous to this element of the flagellar apparatus of the other archamoebae, even though pelomyxae do not have the karyomastigont.

Finally, perinuclear microtubules that are not part of the karyomastigont and that do not originate from the basal bodies of the flagella have been found in Mastigamoeba balamuthi (Chavez et al., 1986). Besides, in the karyomastigont of $M$. hylae there are microtubules arising not from the kinetosome but from the outer nuclear membrane (Brugerolle, 1982). Thus, the nuclear envelope seems to play the role of a MTOC in this archamoeba, too.

To sum up, at least three patterns of microtubular cytoskeleton can be identified in species of the genus Pelomyxa based on the data obtained in this study. In $P$. gruberi and P. prima the cytoplasm is structured by numerous bundles of microtubules, which may start both from the kinetosomes and from the nuclear envelope. There is no connection between the fla- 
gellar rootlets and the nuclei in these two species. $P$. belevskii has few perinuclear microtubules, and the main component of its tubulin cytoskeleton are long dense bundles of microtubules starting from the kinetosomes and going into the cytoplasm in various directions. In $P$. binucleata, $P$. stagnalis and $P$. palustris the leading role in the cytoskeleton formation is played by cytoplasmic microtubules proper, which form a more or less developed network structuring the entire cytoplasmic volume. In these species, there are few microtubules associated with kinetosomes, they are rather short and mostly lie in the peripheral layers of the cytoplasm, usually directly under the cell membrane.

\section{Acknowledgments}

The authors are grateful to Dr. Andrew Goodkov for valuable discussions and help with the editing of the manuscript and to Natalia Lentsman for linguistic assistance. The work was partly supported by Budgetary Program AAAA-A19-119020690109-2 (Zoological Institute RAS). The research was partly performed at the Research Park of St. Petersburg State University ("Centre for Culture Collection of Microorganisms").

\section{References}

Berdieva M.A., Chistyakova L.V., Miteva O.A., Frolov A.O. and Goodkov A.V. 2015. Light- and electron-microscopic study of pelobiont Pelomyxa secunda (Gruber, 1884) comb. nov. (Archamoebae, Pelobiontida). Cell Tissue Biol. 9, 158-165.

Berdieva M., Pozdnyakov I., Matantseva O., Knyazev N. and Skarlato S. 2018. Actin as a cytoskeletal basis for cell architecture and a protein essential for ecdysis in Prorocentrum minimum (Dinophyceae, Prorocentrales). Phycological Res. 66, 127-136.

Brugerolle G. 1982. Caracteres ultrastructuraux d'une mastigamibe: Mastigina hylae (Frenzel). Protistologica. 18, 227-235.

Cavalier-Smith T., Fiore-Donno A.M., Chao E., Kudryavtsev A., Berney C., Snell E. A. and Lewis R. 2015. Multigene phylogeny resolves deep branching of Amoebozoa. Mol. Phylog. Evol. 83, 293-304.

Cavalier-Smith T., Chao E. and Lewis R. 2016. 187-gene phylogeny of protozoan phylum Amoebozoa reveals a new class (Cutosea) of deep- branching, ultrastructurally unique, enveloped marine Lobosa and clarifies amoeba evolution. Mol. Phylog. Evol. 99, 275-296.

Chavez L.A., Balamuth W. and Gong T. 1986. A light and electron microscopical study of a new, polymorphic free-living amoeba, Phreatamoeba balamuthi n. g., n. sp. J. Protozool. 33, 397-404.

Chistyakova L.V. and Frolov A.O. 2011. Light and electron microscopic study of Pelomyxa stagnalis sp. n. (Archamoebae, Pelobiontida). Cell Tissue Biol. 5, 90-97.

Chystyakova L.V., Miteva O.A. and Frolov A.O. 2012. Morphology of Mastigamoeba aspera Schulze, 1875 (Archamoebae, Pelobiontida). Cell Tissue Biol. 6, 189-196.

Chistyakova L.V., Miteva O.A., Frolov A.O. and Skarlato S.O. 2013. Comparative morphology of the subphilum Conosa Cavalier-Smith 1998. Tsitologiya. 11, 778-787 (in Russian with English summary).

Chistyakova L.V., Berdieva M.A., Frolov A.O. and Goodkov A.V. 2014. Reisolation and redescription of pelobiont Pelomyxa paradoxa Penard, 1902 (Archamoebae, Pelobiontida). Cell Tissue Biol. 8, 504-512.

Fritz-Laylin L. K. and Fulton C. 2016. Naegleria: a classic model for de novo basal body assembly. Cilia. 5: 10. https://doi.org/10.1186/s13630-0160032-6.

Frolov A.O. 2011. Pelobiontida (Page, 1976) Griffin, 1988. In: Protists. V. 3. Nauka, SPb, pp. 270-307 (in Russian).

Frolov A., Chystjakova L. and Goodkov A. 2004. A new pelobiont protist Pelomyxa corona sp. n. (Peloflagellatea, Pelobiontida). Protistology. 3, 233-241.

Frolov A.O., Chistyakova L.V., Malysheva M.N. and Goodkov A.V. 2005a. Light and electron microscopic investigation of Pelomyxa prima (Gruber, 1884) (Peloflagellatea, Pelobiontida). Tsitologiya. 47, 89-98 (in Russian with English summary).

Frolov A., Chystjakova L. and Goodkov A. 2005b. A light- and electron-microscopical study of Pelomyxa binucleata (Gruber, 1884) (Peloflagellatea, Pelobiontida). Protistology. 4, 57-73.

Frolov A., Goodkov A., Chystjakova L. and Skarlato S. 2006. Morphology and development of Pelomyxa gruberi sp. n. (Peloflagellatea, Pelobiontida). Protistology. 4, 227-244.

Frolov A.O., Chistyakova L.V., Goodkov A.V. and Malysheva M.N. 2007. Morphological study of cysts of Pelomyxa palustris Greeff, 1874. Cell Tissue Biol. 1, 457- 466. 
Frolov A.O., Chystyakova L.V. and Malysheva M.N. 2011. Light and electron microscopic study of Pelomyxaflavasp. n. (Archamoebae, Pelobiontida). Cell Tissue Biol. 5, 81-89.

Goodkov A.V. 1989. Ultrastructure of the giant amoeba Pelomyxa palustris. I. Cytoplasmic microtubules, subcentrioles, and flagella: a comparative morphological analysis of organization. Tsitologiya. 31, 371-379 (in Russian with English summary).

Goodkov A.V., Chistyakova L.V., Seravin L.N. and Frolov A.O. 2004. The concept of pelobionts (class Peloflagellatea): a brief history and current status. Zool. Zh. 83, 643-654 (in Russian with English summary).

Griffin J.L. 1988. Fine structure and taxonomic position of giant amoeboid flagellate Pelomyxa palustris. J. Protozool. 35, 300-315.

Haskins E. F. and McGuinness M. D. 1988. Ultrastructure of the flagellar apparatus of the slime mold Semimorula liquescens. Mycologia. 80, 630635.

Ishigami M.A.1977. Light and electron microscopic study of the flagellate-to-ameba conversion in the myxomycete Stemonitis pallida. Protoplasma. 91, 31-54.

Johnson U.G. and Porter K.R. 1968. Fine structure of cell division in Chlamydomonas reinchardi. Basal bodies and microtubules. J. Cell. Biol. 38, 403-425.

Kang S., Tice A. K., Spiegel F. V., Silberman J. D., Panek T., Čepička I., Kostka M., Kosakyan A., Alcantara D. M. C., Roger A. J., Shadwick L. L., Smirnov A., Kudryavtsev A., Lahr D. J. R. and Brown M. W. 2017. Between a pod and a hard test: The deep evolution of amoebae. Mol. Biol. Evol. 34, 2258-2270.

Mayne R. and Adamatzky A. 2015. Slime mould foraging behaviour as optically coupled logical operations. Int. J. Gen. Syst. 44, 305-313.

Nývltová E., Šuták R., Harant K., Šedinová M., Hrdý I., Pačes J., Vlček Č. and Tachezy J., 2013. NIF-type iron-sulfur cluster assembly system is duplicated and distributed in the mitochondria and cytosol of Mastigamoeba balamuthi. Proc. Natl. Acad. Sci. USA. 110, 7371-7376.

Panek T., Zadrobílková E., Walker G., Brown M. W., Gentekaki E., Hroudova M., Kang S., Roger A. J., Tice A. K., Vlcek C. and Čepička I. 2016. First multigene analysis of Archamoebae (Amoebozoa: Conosa) robustly reveals its phylogeny and shows that Entamoebidae represents a deep lineage of the group. Mol. Phylog. Evol. 98, 41-51.
Ptáčková E., Kostygov A., Chistyakova L., Falteisek L., Frolov A., Patterson D., Walker G. and Čepička I. 2013. Evolution of archamoebeae: morphological and molecular evidence for pelobionts including Rhizomastix, Entamoeba, Iodamoeba, and Endolimax. Protist. 164, 380-410.

Seravin L.N. and Goodkov A.V. 1987. The flagella of the freshwater amoeba Pelomyxa palustris. Tsitologiya. 29, 721-724 (in Russian with English summary).

Simpson P. A and Dingle A. D. 1971. Variable periodicity in the rhizoplast of Naegleria flagellates. J. Cell Biol. 51, 323-328.

Simpson A.G.B., Bernard C., Fenchel T. and Patterson D.J. 1997.The organization of Mastigamoeba schizophrenia $\mathrm{n}$. sp.: more evidence of ultrastructural idiosyncrasy and simplicity in pelobiont protists. Eur. J. Protistol. 33, 87-98.

Spiegel F.W. 1981. Phylogenetic significance of the flagellar apparatus in Protostelids (Eumycetozoa). BioSystems. 14, 491-499.

Spiegel F.W. 1991. A proposed phylogeny of the flagellated protostelids. BioSystems. 25, 113-120.

Spiegel F.W. and Feldman J. 1985. Obligate amoebae of the protostelids: significance for the concept of Eumycetozoa. BioSystems. 18, 377-386.

Tovar J., Fischer A. and Clark C.G. 1999. The mitosome, a novel organelle related to mitochondria in the amitochondrial parasite Entamoeba histolytica. Mol. Microbiol. 32, 1013-1021.

Walker G., Simpson A.G.B., Edgcomb V., Sogin M.L. and Patterson D.J. 2001. Ultrastructural identities of Mastigamoeba punctachora, Mastigamoeba simplex and Mastigella commutans and assessment of hypotheses of relatedness of the pelobionts (Protista). Eur. J. Protistol. 37, 15-25.

Whatley J.M. and Chapman-Andresen C. 1990. Phylum Karyoblastea. In: Handbok of Protoctista. (Eds. J.O. Corliss, M. Melkonian and D.J. Chapman). Boston, Jones and Bartlett Publ., pp. 167185.

Wright M., Mir L. and Moisand A. 1980. The structure of the pro-flagellar apparatus of the amoebae of Physarum polycephalum: relationship to the flagellar apparatus. Protoplasma. 103, 69-81.

Zadrobílková E, Walker G. and Čepička I. 2015. Morphological and molecular evidence support a close relationship between the freeliving archamoebae Mastigella and Pelomyxa. Protist. 166, 14-41.

Zadrobílková E., Smejkalová P., Walker G. and Čepička I. 2016. Morphological and molecular 
diversity of the neglected genus Rhizomastix Alexeieff, 1911 (Amoebozoa: Archamoebae) with description of five new species. J. Eukar. Microb. 63, 181-197.

Address for correspondence: Ludmila Chistyakova. Zoological Institute, Russian Academy of Sciences, Universitetskaya Emb. 1, 199034 St. Petersburg, Russia; e-mail: pelomixa@mail.ru 